\title{
Cardiac Involvement in Non-Hodgkin Lymphoma, an Incidental Large Atrial Mass: A Case Report
}

\author{
Seyed Amir Aledavood, ${ }^{1}$ Ali Emadi Torghabeh, ${ }^{1, *}$ Fateme Homaee Shandiz, ${ }^{1}$ and Bahram \\ Memar $^{2}$ \\ ${ }^{1}$ Cancer Research Center, Faculty of Medicine, Mashhad University of Medical Sciences, Mashhad, IR Iran \\ ${ }^{2}$ Department of Patholgy, Emam Reza Hospital, Mashhad University of Medical Sciences, Mashhad, IR Iran \\ *Corresponding author: Ali Emadi Torghabeh, Cancer Research Center, Faculty of Medicine, Mashhad University of Medical Sciences, Mashhad, IR Iran. Tel: +98-5134222125, \\ E-mail: emadita1@mums.ac.ir
}

Received 2015 August 24; Accepted 2015 September 29

\begin{abstract}
Introduction: Cardiac involvement as an initial presentation of malignant lymphoma has been a rare occurrence.

Case Presentation: We have reported a 78 year old man with complaint of abdominal pain and vomiting. In patients preoperative evaluation for surgical management of an intra-abdominal mass, a large intracardiac mass has found incidentally during the echocardiography. Pathologic biopsy of right atrial mass that has removed by open heart surgery shown: non Hodgkin-B cell lymphoma. Bone marrow biopsy was taken and was positive for lymphomatous involvement.

Conclusions: The patient has treated by CHOP chemotherapy regiment successfully and after completion of treatment, there was complete response.

Keywords: Cardiac Mass, CHOP Regimen, Echocardiography, Lymphoma
\end{abstract}

\section{Introduction}

Lymphoma has represented $13.6 \%$ of metastatic tumors to the heart (1). Gross tumor formation in any of the cardiac chambers has been rare, particularly at the time of presentation and diagnosis of lymphoma (2). Symptoms were usually very subtle and non-specific, particularly in the setting of co-existing comorbidities (3). As imaging modalities and treatment options for lymphoma have improved, more unusual disease presentation might be observed more frequently. In this article we have reported a 78-year-old man with an incidental large cardiac mass whose symptoms was abdominal pain and vomiting in the setting of pre-operative evaluation for surgical management of intra-abdominal mass.

\section{Case Presentation}

A 78-year-old man has affected by abdominal pain, vomiting and weakness and has evaluated at June 2013. Studying his medical history, he had hip joint replacement surgery, then in initial physical examination has shown no significant finding, except a few tenderness on the middle abdominal quadrant. In laboratory assessment, complete blood count, renal function tests-alkaline phosphatase and lactate dehydrogenase were normal, but hemoglobin and transaminases were abnormal as follows: $\mathrm{Hb}=9.1 \mathrm{mg} / \mathrm{dl}, \mathrm{AST}=71 \mathrm{u} / \mathrm{lit}, \mathrm{ALT}=656 \mathrm{u} / \mathrm{lit}$.
In abdominal CT scan, there was a $71 \times 61 \mathrm{~mm}$ mass at the aortic bifurcation in favor of tumoral lesion or adenopathy. Surgery has recommended and in pre-operative evaluation he has referred to cardiologist. ECG had no significant and specific changes and in echocardiography, a large mass with diameter of $74 \times 60 \mathrm{~mm}$ has seen in right atrium (Figure 1) and LV ejection fraction was 65\%. Also, in thoracic sections of CT scan, an intra-cardiac mass has seen (Figure 2).

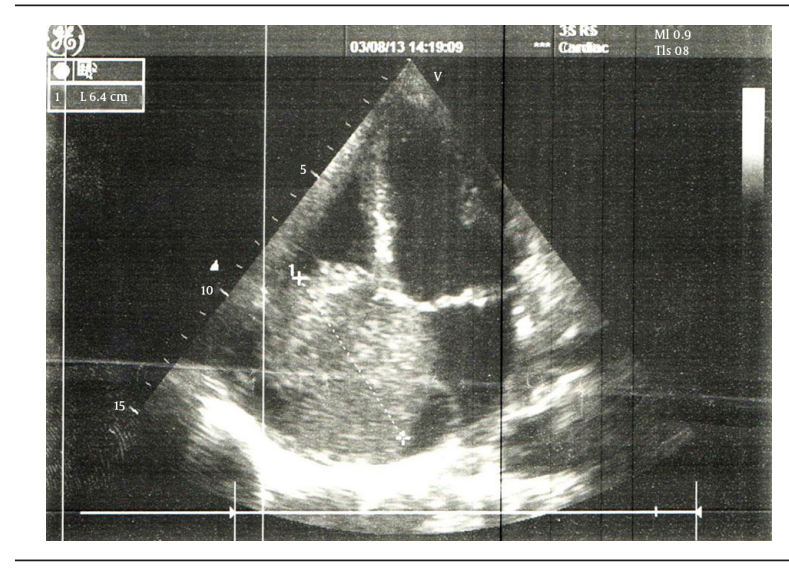

Figure 1. Right Atrial Mass on Echocardiography

Copyright (C) 2015, Iranian Journal of Cancer Prevention. This is an open-access article distributed under the terms of the Creative Commons Attribution-NonCommercial 4.0 International License (http://creativecommons.org/licenses/by-nc/4.0/) which permits copy and redistribute the material just in noncommercial usages, provided the original work is properly cited. 


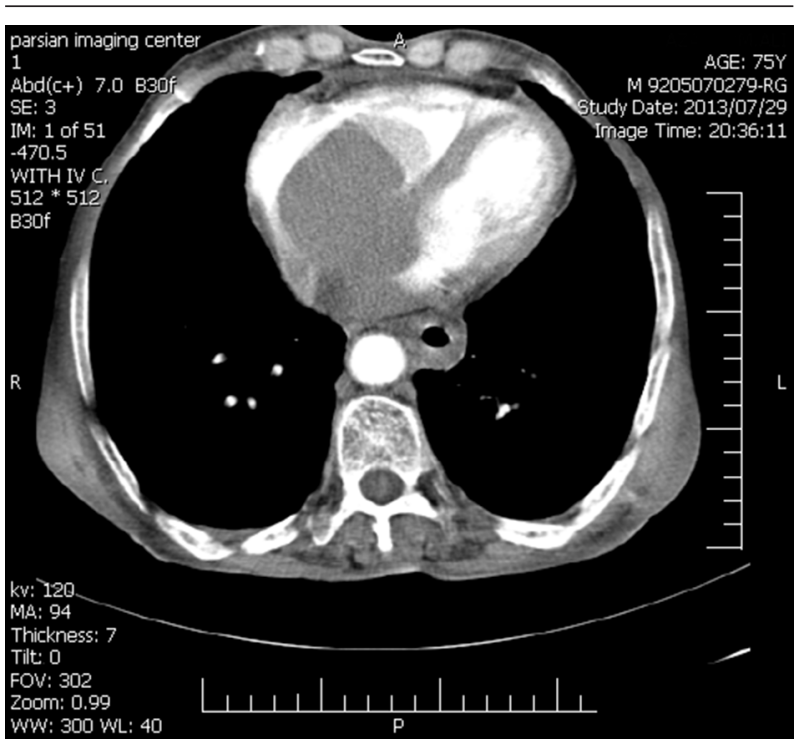

Figure 2. Intracardiac Mass on Thoracic CT Scan

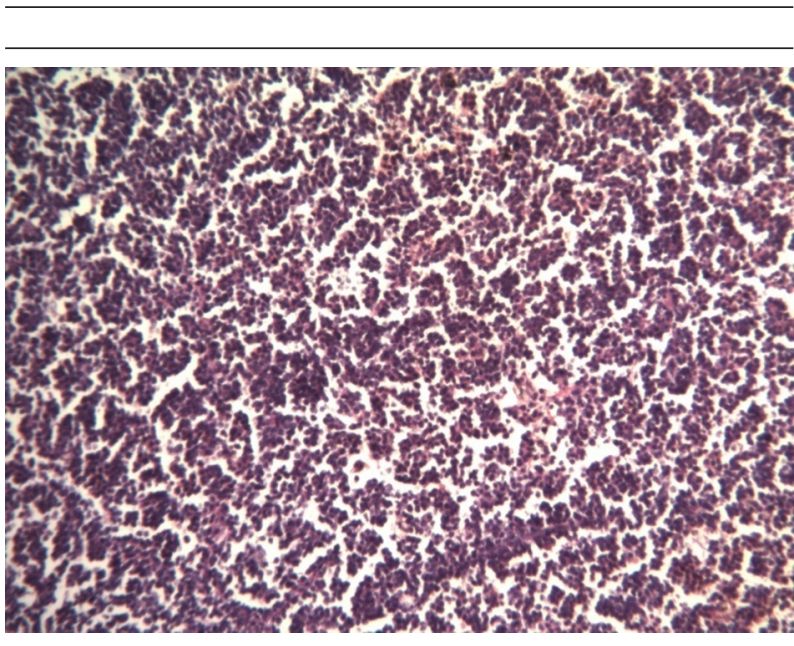

Figure 3. Diffuse Infiltration of Lymphoid Cells (H and E, $\times 100)$

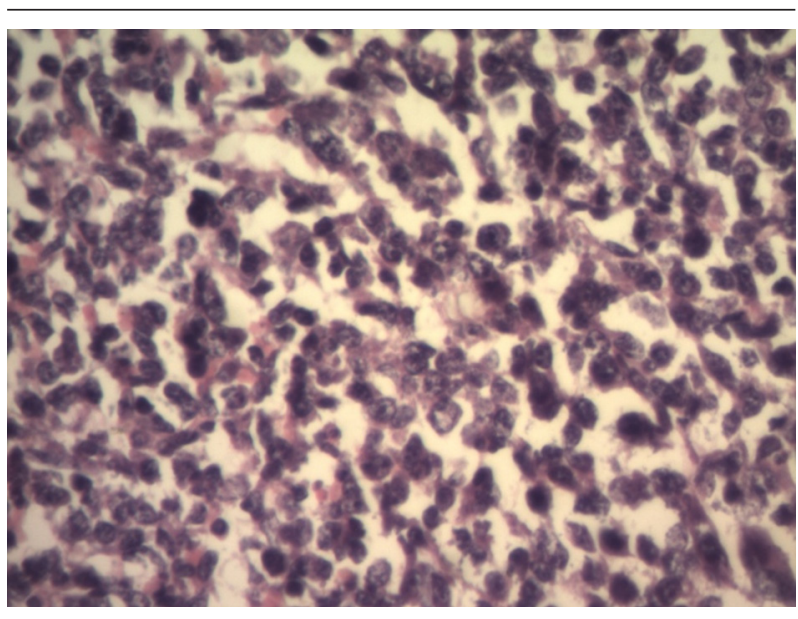

Figure 4. Small to Medium Sized Lymphoid Cells With Round to Irregular Nuclei and Some With Prominent Nucleoli (H and E, $\times 400$ )
Bases on these new findings management of the patient has changed to cardiac surgery and open heart surgery has recommended and performed at August 2013. Pathologic examination of removed cardiac mass has reported as below after immunohistochemistry study: HMB 45 and CK: negative; CD20: positive. Compatible with nonHodgkin lymphoma in favor of B-cell origin (Figures 3 and 4). He has referred to oncologist after recovery of heart surgery (September 2013).

In evaluation of medical history and further physical examination, he had no history of fever and sweating, but weight loss of 2 - $3 \mathrm{~kg}$ during recent weeks. Karnowsky performance status was $80 \%$. At physical examination, he had an adenopathy of $2 \times 1 \mathrm{~cm}$ at left jugulodigastric chain, and the another of $3 \times 1 \mathrm{~cm}$ at left supraclavicular area and physical exam was normal otherwise.

In bone marrow biopsy, BM was hyper cellular, and involved with lymphoma infiltration. The patient has planned to treat by R-CHOP chemotherapy regimen (Rituximab-cyclophosphamide-Doxorubicin-vincristineprednisolone).

He could not provide Rituximab due to economic problems, therefor he has received only CHOP regimen. After first cycle of treatment, cervical adenopathies have disappeared and at the end of seventh cycle, imaging of the neck, chest and abdominopelvic cavity by CT scan had no positive finding of disease but the patient has not satisfied to undergo BM biopsy for second time.

Patient treatment has completed after eight cycles of CHOP chemotherapy regimen at February 2014, but he was in good condition, without any evidences of disease after six months of follow up.

\section{Discussion}

Cardiac masses have been arising from the heart or pericardium, were potentially lethal whether defined as benign or malignant. Almost $75 \%$ of primary cardiac masses were benign. The most common primary malignant tumors were sarcomas and lymphomas (4).

Metastatic deposits have represented the vast majority of cardiac malignancies; the common primary malignancies sources have included cancers of lung, esophagus and breast as well as lymphoma, leukemia and melanoma (5). Cardiac involvement as an initial presentation of malignant lymphoma was a rare occurrence (2). Secondary involvement of the heart has seen in $8.7-27.2 \%$ of documented clinical case of lymphoma $(2,6,7)$. Despite its life-threatening nature (8), the cardiac manifestations of lymphomatous involvement of the heart were often subclinical $(9,10)$. As in the present case there has been no cardiac symptom or sign. These symptoms and signs might include arrhythmias, pericardial effusion or tamponade, tumor embolization and obstruction of blood flow and valvular dysfunction. These symptoms have related on tumor location, size, growth rate, degree of invasion and friability. 
In the present case and many other reports the majority of intracavital tumors have occurred on the right site of the heart, the reason for which has yet been to be found $(1,11)$. Plain chest radiographs lack sensitivity and specificity as an initial diagnostic tool but could demonstrate cardiomegaly or specific chamber enlargement. Echocardiography was the first non-invasive study for examining the chambers of the heart and pericardium (12) but trans esophageal echocardiography (TEE) was a more sensitive technique for assessing patients (13).

CT scan and MRI with gadolinium contrast injection were useful tools for demonstrating morphology, location, extension of disease, blood flow and cardiac function $(14,15)$. FDG-PET imaging has recently reported to reveal previously unsuspected cardiac involvement $(16,17)$. Pathologic diagnosis has been essential in management of cardiac masses. Although traditionally this has required a thoracostomy, less invasive procedures has recently been available such as TEE-guided biopsy, endomyocardial biopsy, or percutaneous intracardiac biopsy with combined fluoroscopy and TEE or pericardial fluid sampling $(18,19)$.

Because of rarity, data has been lacking to produce definitive guidelines regarding management. The available literature suggested systemic chemotherapy was the only effective therapy (18) and the majority of cases have treated with combination chemotherapy with varying results $(20,21)$. There was an improvement in response and survival rates by adding of monoclonal therapies to chemotherapy (22). Radiation therapy has indicated in cardiac mass that progresses despite chemotherapy and its adverse side effects have been pericarditis, cardiomyopathy, diastolic dysfunction, conduction defects and coronary artery disease. Radical surgery has not advised.

Lymphomatous involvement of the heart has reported with greater frequency than the past. Cardiac involvement was rare as an initial presentation of malignant lymphoma and has often been subclinical. These tumors have seen more common in the right site of the heart and TEE, CT scan and MRI with Gd were effective tools in assessment of patients. Pathologic diagnosis would be essential to management of cardiac masses and the only effective treatment has been chemotherapy.

\section{Acknowledgments}

Thanks to Mrs. Jangi for typing and editing of this article.

\section{Footnotes}

Authors' Contribution:Ali Emadi Torghabeh has designed the study, collected the data and written the paper. Seyed Amir Aledavood has contributed to analysis and literature review. Fateme Homaee Shandiz has contributed to the patient treatment and follow-up and Bahram Me- mar has contributed to providing pathologic evidences. Conflict of Interest:There is no conflict of interest. Financial Disclosure:There is no financial disclosure.

\section{References}

1. Lam KY, Dickens P, Chan AC. Tumors of the heart. A 20-year experience with a review of 12,485 consecutive autopsies. Arch Pathol Lab Med.1993;117(10):1027-31. [PubMed: 8215825]

2. Tanaka T, Sato T, Akifuji Y, Sakamoto M, Shio H, Ueki J, et al. Aggressive non-Hodgkin's lymphoma with massive involvement of the right ventricle. Intern Med. 1996;35(10):826-30. [PubMed: 8933196]

3. Zaharia L, Gill PS. Primary cardiac lymphoma. Am J Clin Oncol. 1991;14(2):142-5. [PubMed: 2028920]

4. Grebenc ML, Rosado de Christenson ML, Burke AP, Green CE, Galvin JR. Primary cardiac and pericardial neoplasms: radiologicpathologic correlation. Radiographics. 2000;20(4):1073-103. doi: 10.1148/radiographics.20.4.g00jl081073. [PubMed:10903697]

5. Chiles C, Woodard PK, Gutierrez FR, Link KM. Metastatic involvement of the heart and pericardium: CT and MR imaging. Radiographics. 2001;21(2):439-49. doi: 10.1148/ radiographics.21.2.g01mr15439. [PubMed:11259706]

6. Rosenberg SA, Diamond HD, Jaslowitz B, Craver LF. Lymphosarcoma: a review of 1269 cases. Medicine (Baltimore). 1961;40:31-84. [PubMed:13743408]

7. Roberts WC, Glancy DL, DeVita VT, Jr. Heart in malignant lymphoma (Hodgkin's disease, lymphosarcoma, reticulum cell sarcoma and mycosis fungoides). A study of 196 autopsy cases. Am J Cardiol. 1968;22(1):85-107. [PubMed: 4873149]

8. Saotome M, Yoshitomi Y, Kojima S, Kuramochi M. Primary cardiac lymphoma--a case report. Angiology. 2002;53(2):239-41. [PubMed:11952118]

9. Terasawa A, Sugihara S, Itoh K. Malignant lymphoma presenting as a cardiac tumor. Japan heart j. 1991;3:183-9.

10. Saito T, Tamaru J, Kayao J, Kuzuu Y, Wakita H, Mikata A. Cytomorphologic diagnosis of malignant lymphoma arising in the heart: a case report. Acta Cytol. 2001;45(6):1043-8. [PubMed:11726101]

11. Menendez A, Gonzalez A, Cabrera H, Mesa J, Martinez G, Espinoza E, et al. Clinical spectrum of extramedullary acute promyelocytic leukemia. Eur J Haematol. 2000;64(3):201-3. [PubMed:10997887]

12. Majano-Lainez RA. Cardiac tumors: a current clinical and pathological perspective. Crit Rev Oncog. 1997;8(4):293-303. [PubMed: 9622051]

13. Meng Q, Lai H, Lima J, Tong W, Qian Y, Lai S. Echocardiographic and pathologic characteristics of primary cardiac tumors: a study of 149 cases. Int J Cardiol. 2002;84(1):69-75. [PubMed: 12104067]

14. Hoffmann U, Globits S, Schima W, Loewe C, Puig S, Oberhuber G, et al. Usefulness of magnetic resonance imaging of cardiac and paracardiac masses. Am J Cardiol. 2003;92(7):890-5. [PubMed: 14516903]

15. Wang ZJ, Reddy GP, Gotway MB, Yeh BM, Hetts SW, Higgins CB. CT and MR imaging of pericardial disease. Radiographics. 2003;23 Spec No:S167-80. doi:10.1148/rg.23si035504. [PubMed:14557510]

16. Nguyen JD, Carrasquillo JA, Little RF, Ryan QC, Wilson W, Chen CC. Fluorodeoxyglucose positron emission tomography in the presence of cardiac metastases. Clin Nucl Med. 2003;28(12):97980. doi: 10.1097/01.rlu.0000099808.30653.06. [PubMed: 14663321]

17. Romer W, Garbrecht M, Fuchs C, Schwaiger M. Images in cardiovascular medicine. Metabolic imaging identifies non-Hodgkin's lymphoma infiltrating heart. Circulation. 1998;97(25):2577-8. [PubMed: 9657480]

18. Ceresoli GL, Ferreri AJ, Bucci E, Ripa C, Ponzoni M, Villa E. Primary cardiac lymphoma in immunocompetent patients: diagnostic and therapeutic management. Cancer. 1997;80(8):1497-506. [PubMed: 9338475]

19. Jurkovich D, de Marchena E, Bilsker M, Fierro-Renoy C, Temple D, Garcia H. Primary cardiac lymphoma diagnosed by percutaneous intracardiac biopsy with combined fluoroscopic and trans- 


\section{Aledavood SA et al.}

esophageal echocardiographic imaging. Catheter Cardiovasc Interv. 2000;50(2):226-33. [PubMed:10842397]

20. Ikeda H, Nakamura S, Nishimaki H, Masuda K, Takeo T, Kasai $\mathrm{K}$, et al. Primary lymphoma of the heart: case report and literature review. Pathol Int. 2004;54(3):187-95. doi: 10.1111/j.14401827.2003.01606.x. [PubMed:14989742]

21. Knowles JW, Elliott AB, Brody J. A case of complete heart block reverting to normal sinus rhythm after treatment for cardiac invasive Burkitt's lymphoma. Ann Hematol. 2007;86(9):687-90. doi: 10.1007/s00277-007-0290-x. [PubMed:17410366]

22. Nakagawa Y, Ikeda U, Hirose M, Ubukata S, Katsuki TA, Kaminishi Y, et al. Successful treatment of primary cardiac lymphoma with monoclonal CD20 antibody (rituximab). Circ J. 2004;68(2):172-3. [PubMed:14745155] 